\title{
Factors associated with the relationship between non-fatal road injuries and economic growth
}

\begin{abstract}
This study reports the results of an empirical analysis of the Kuznets curve relationship between non-fatal road injuries and per-capita income. This relationship indicates that the number of road deaths increases with increasing per-capita income at lower income levels, but decreases once it has exceeded a threshold level. We apply a fixed effects negative binomial regression analysis on a panel of 90 countries over the period of 1963 ï 2009. Results indicated evidence of an inverted U-shaped relationship between economic growth and nonfatal road injuries for both less developed and highly developed countries. Results also indicated that the turning point is higher in less developed countries than in higher developed countries. The evidence presented in this study suggests that improvements in road infrastructure, the quality of regulatory institutions, and increase in the use of safer transport modes will help reduce non-fatal road injuries.
\end{abstract}

Keyword: Kuznets relationship; Non-fatal road injuries; Democracy; Political stability 